\title{
Los orígenes de la industria española de los forasteros
}

\author{
Juan Carlos GonzÁlez Morales \\ Universidad Carlos III \\ jzalez@carpetaniamadrid.com
}

Recibido: $25 / 05 / 2015$

Aceptado: 03/07/2015

\section{Resumen}

La llegada de forasteros a nuestro país no era una empresa fácil de acometer en una España en crisis después de 1898, dividida políticamente entre conservadores y liberales, y con serias carencias en sus infraestructuras y transportes. La actividad comercial española necesitaba nuevos frentes y el turismo podría convertirse en un importante factor y motor mercantil.

La búsqueda y la construcción en torno a ese objetivo comenzó a partir de 1905, cuando la iniciativa pública y privada realizaron las primeras gestiones encaminadas a este fin, y se constituyen se constituyeron sociedades-sindicatos, según el modelo francés, para fomentar la afición por los viajes y la recepción de viajeros.

Palabras clave: viaje, viajeros, turismo, turistas, forastero, excursionista, guías, congresos, agencias, la industria de lo pintoresco, la industria de los forasteros.

\section{The Spanish Industry of Foreigners at its Origins}

\begin{abstract}
The arrival of foreigners to our country was not an easy task to undertake in a Spain in crisis after 1898, politically divided between conservatives and liberals and with serious gaps in transport infrastructure. The Spanish business needed new fronts and tourism could become an important factor and commercial driver.

Searching and building around that goal starts from 1905 in when public and private initiative made the first steps towards this end, and societies-unions are constituted according to the French model to promote the passion for travel and reception of travelers.
\end{abstract}

Key words: Travel, Travelers, Tourism, Tourist, Stranger, Hiking, Guides, Conferences, Agencies, the Industry of the Piscturesque, Industry of Foreigners. 
'Esta maravillosa diversidad de aspectos y paisajes, verdadero banquete de dioses con que España brinda al viajero con una mágica reproducción y síntesis del Cosmos bastaría a hacer de ella centro privilegiado del turismo

Blanca DE LOS Ríos DE LAMPÉREZ

\section{La España de viajeros del XIX}

Tiene el castellano palabra definidora de estos peregrinos laicos, la registra el Diccionario académico, mas nunca fue usual. Tres son las causas que mueven a viajar: necesidad, oficio y gusto. Llámase viajero al sujeto de la primera acción; viajante, el de la segunda, y el de la tercera, viajador, vocablo que debiera difundirse para destierro de turista, que es feo galicismo ${ }^{1}$.

Francisco JAVIER SÁNCHEZ CANTÓN

Pensar en España en el siglo XIX era pensar en un país exótico. Para el visitante europeo es un nexo de unión con lo africano, lleno de referencias y perfumes árabes, desiertos, misterios y el embrujo de lo exótico. El mayor atractivo de su espacio no reside en el patrimonio o en la naturaleza, sino en ese sabor diferente y casi prohibido. Es una nación devastada por las múltiples guerras sufridas a lo largo del siglo XIX - guerras contra franceses, entre partidarios de bandos diversos y de monarcas diferentes y luchas por el poder- que mira cómo reconstruirse más que mirar al exterior. Durante el el siglo XIX recibe aventureros, escritores, artistas, y hasta vendedores de biblias, en busca de inspiración, de nuevos destinos o de un viaje al margen de lo cotidiano. Lejos están todavía los tiempos en que estas visitas se estructurarán como negocio, que se hable de instituir una industria para los forasteros.

Dentro de la geografía española, Andalucía poseía un atractivo casi mitológico para los viajeros románticos que cruzaban Europa y llegaban finalmente al Sur de España, atravesando el puerto de Despeñaperros para encontrarse con monumentos bellos e inspiradores como la Alhambra de Granada, La Mezquita de Córdoba o el Alcázar de Sevilla.

Hay numerosos testimonios literarios de viajeros como los de Richard Ford -Handbook for travellers in Spain and readers at home (1845)2-, George Borrow -La Biblia en España ${ }^{3}$-, Washington Irving -Cuentos de la Alhambra-, Edgar Qimet, Edmundo De Amicis - La Spagna (España, viaje durante el reinado de Don Amadeo I de Saboya)-, Victor Hugo, Teófilo Gautier, Rubén Darío, Faustino Sarmiento, etc. que construyen el imaginario español y alimentan la imagen tópica de que toda España es como Andalucía.

En estos testimonios aparecen visiones y sensaciones cargadas de ingredientes

1 SÁNCHEZ CANTÓN, Francisco Javier: "El viaje de España y el arte español: Centenario de Don Antonio Ponz", Revista de Occidente, Madrid, 1925, abril-mayo- junio, tomo VIII, núm. 24, pp. 307-329.

2 "De las muchas tergiversaciones de que es objeto España, pocas han circulado de manera más sistemática que la referente a las dificultades y peligros que acosan al viajero. Este país, es el más característico y romántico de Europa, puede visitarse a todo lo largo y ancho de su extensión con facilidad y seguridad". FORD, Richard: Manual para viajeros en España y lectores en casa. Madrid, Biblioteca Turner, 2009.

3 "En estas partes todo tiene un carácter enteramente oriental" BORROW, George: La Biblia en España, Madrid, Alianza Editorial, 1970. 
exóticos y novedosos para los europeos: los gitanos, la belleza moruna de la mujer española, la pasión por los toros, los bandoleros... y destinos como Cádiz, Málaga, Sevilla, Barcelona -la más cercana a Europa-, Madrid -sede de la Corte española y centro administrativo que posee el Museo del Prado, que deslumbra con sus obras de arte- y San Sebastián, que a finales de siglo XIX era una ciudad distinguida, famosa por sus aguas y por sus noches de juegos y apuestas.

\section{De las guías de forasteros a las guías de viajeros y turistas}

A lo largo del siglo XIX proliferan junto a las guías de forasteros, publicaciones de carácter informativo, habituales en cualquier ciudad y que proporcionan todo tipo de informaciones prácticas. Otras novedosas publicaciones denominadas guías de viaje destinadas a los viajeros que se desplazaban por recreo y que demandaban un nuevo tipo de guía que facilitara sus desplazamientos y estancias.

Estas nuevas guías poseen un carácter turístico, y proporcionan indicaciones prácticas para el viaje: itinerarios para visitar lo más notable de los lugares hasta donde llega el viajero, información sobre los servicios de ferrocarriles, carreteras, caminos, sendas y veredas; lugares para alojarse, noticias y recomendaciones útiles para los viajeros. Entre las guías editadas destacan las Baedeker -las más populares ${ }^{4}$, Joanne, Murray y Hachette. Con el paso del tiempo, además de incrementarse la publicación de este tipo de guías, se diversificarán y especializarán. Aparecen guías publicadas por las compañías de ferrocarriles, guías indicadores de poblaciones, de balnearios, locales, artísticas, anuarios de clubes (ciclismo, automovilismo, alpinismo...) y algunas de ellas se editarán en diferentes idiomas. Las guías se convierten en una parte del equipaje de viaje 5 .

4 La primera guía Baedeker data de 1839. En 1898 se publicó la Guía de España y Portugal (en alemán), editándose por segunda vez en 1899, a la que seguirían otras en 1908 y años posteriores. BAEDEKER: Espagne et Portugal. Manuel du voyageur, Leipzig, 1913, vol. 1, 4 Ed.

5 "La guía del viajero, por otra parte no sirve solo para satisfacer la curiosidad de los que viajan, sino que también es un libro útil y agradable para los que quieran conocer nuestro país sin recorrerlo, porque así los caminos, como los pueblos y las comarcas, están de tal manera descritos, que bien puede el lector sentado en su gabinete hacerse la ilusión de que los va visitando; y esto explica la razón por que la guía del viajero ha sido traducida a varios idiomas, y se vende en número considerable de ejemplares en cada edición en el extranjero".

P. MELLADO, Francisco: Guía del viajero en España, Madrid, Imprenta de Chaulie, 1869. 


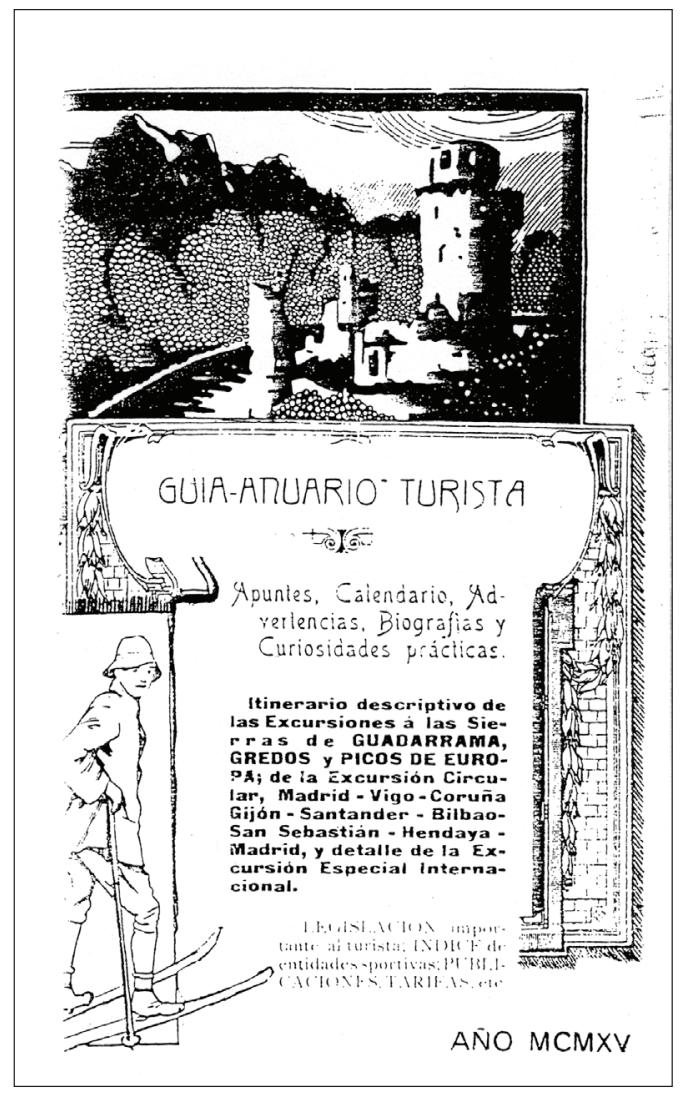

Fig. 1. GUÍA-ANUARIO-TURISTA (Cubierta). Gonzalvo Burgoa, Celestino E. Madrid: Est. Tip. M. Dávila, 1915. Obra de consulta realizada con arreglo cronológico, histórico y artístico sobre la ciudades y lugares más pintorescos de España.

Colección particular Juan Carlos González Morales.

De forma paralela a la edición de estas guías de viajes y turismo, comienzan a realizarse folletos, carteles, planos, álbumes fotográficos, portafolios, $\operatorname{postales}^{6}$, que favorecen el hecho de que el lector pueda viajar con la mirada.

Los periódicos comienzan a abordar el mundo de los viajes en sus páginas y dedican secciones fijas ${ }^{7}$. Empezaron a publicarse revistas y semanarios ilustrados dedicados exclusivamente a deportes y turismo ${ }^{8}$. Los medios de comunicación se convierten

6 TEIXIDOR CADENAS, Carlos: La tarjeta postal en España (1892-1915), Madrid, Espasa Calpe, 1999.

Las primeras tarjetas postales ilustradas comienzan a circular en España en el año 1892 y se consolidan entre 1906 y 1915. Durante todo ese periodo de tiempo, la fototipia de los suizos Hauser y Menet se especializa en la producción de series de tarjetas sobre visitas y monumentos de España, costumbres y tipos españoles, asuntos taurinos, bellezas españolas, retratos...

7 La Correspondencia de España, La Época, La Esfera, La Ilustración Española y Americana y Nuevo Mundo.

8 Gran vida: Revista Ilustrada de Sports, Le Touriste... 
en difusores de una nueva actividad económica y de una causa patriótica: transformar España en un núcleo receptor del turismo mundial ${ }^{9}$.

\section{El termalismo y los baños de ola: una práctica terapéutica y recreativa}

Las playas eran espacios abandonados a la acción de la naturaleza, de apariencia casi selvática, que tradicionalmente se habían dedicado al comercio, la navegación, la guerra y el trabajo, adquieren en la cultura del hombre moderno nuevos valores: se convierten en lugares de sensibilización y contemplación estética. El mar pasa a ser un espacio de admiración paisajística ${ }^{10}$-playas, puertos y acantilados sirven de motivo para la inspiración pictórica-, se alaban sus virtudes higiénicas y se transforman sus espacios.

Los enclaves costeros se transforman en centros de ocio a través de la moda higienista y la hidroterapia ${ }^{11}$. Los baños de ola ${ }^{12}$ en el mar se tomaban por prescripción facultativa y la ciencia creía en la talasoterapia. Los médicos recomiendan a sus pacientes visitar las playas y los establecimientos termales. Son espacios de recreo y descanso para la aristocracia y la alta burguesía. La extensión de estos establecimientos y la afluencia de clientes a los mismos alcanzó su momento álgido a finales del siglo XIX. Las estaciones termales y los balnearios eran centros en donde las familias de clases altas y acomodadas acudían para tener una estancia saludable, conocer gente, pasar el tiempo, etc.

Existen dos tipos de balnearios: los balnearios costeros (establecimientos de baños de mar, consistentes en casetas para baños marítimos) y los balnearios de interior. Los primeros se explotan con carácter de concesión y dependen de las corrientes estacionales, mientras que las estaciones termales son complejos permanentes ${ }^{13}$.

La extensión de esta práctica favoreció el desarrollo de una infraestructura vinculada con el ocio, estableciéndose una relación entre salud y turismo. Son los precedentes de turismo residencial y del movimiento turístico que se desarrollará durante el siglo XX. El norte de España es el destino más frecuentado y es la zona donde se construyen más edificios, creándose un urbanismo específico ligado al desarrollo de los balnearios: casetas, kursaales, casinos, kioscos de música, salas de baile, escenarios para representaciones, bibliotecas, terrazas, hotelitos y chalets.

Las vacaciones, el veraneo, los días pasados en la playa, constituyen para el hombre y la mujer modernos la principal posibilidad de romper la monotonía del ciclo coti-

9 “El turismo en España. Una idea patriótica”, Nuevo Mundo, 881, (1910).

10 A la playa. El mar como forma de la modernidad en la pintura española 1870-1936, Fundación cultural Mapfre Vida, Madrid, 2000.

11 LARRINAGA, Carlos: "Termalismo y turismo en la España del siglo XIX" en Barciela, Carlos; Manera, Carles; Molina, Ramón y Di Vittorio, Antonio (eds.): La evolución de la industria turística en España e Italia, Palma de Mallorca, Institut Balear d'Economia, 2011, pp. 569-608.

12 BATALLER Y CONTASTI, A.: Guía del bañista o reglas para tomar con provecho los baños de mar, Barcelona, Imprenta de la Reinaxensa, 1877.

13 Guía Oficial de establecimientos balnearios españoles y aguas medicinales españolas, Asociación Nacional de Propaganda Balnearia, Madrid-Barcelona, Ed. Rudolf Mosse, 1927. 
diano. Este tiempo suspendido o de recreo abre durante un breve periodo de tiempo las puertas a la evasión, a la aventura, a la fiesta, a todo tipo de placeres en suma. [...] El disfrute de la playa es una vivencia que trae la modernidad, un tiempo de ocio que, como otras novedades, comenzó siendo elitista para ir generalizándose poco a poco y masificarse después ${ }^{14}$.

Los balnearios españoles más frecuentados son: Panticosa (Huesca), Archena (Murcia), Fortuna (Murcia), Mondariz ${ }^{15}$ (Pontevedra), La Toja (Pontevedra), Caldas de Malavella (Gerona), Solares (Santander), Marmolejo (Jaén), Caldas de Oviedo (Oviedo), Alhama de Aragón (Zaragoza), Busot (Alicante), Baños de Montemayor (Cáceres), Vichy Catalán (Barcelona), Lanjarón (Granada), Medina del Campo (Valladolid), etc ${ }^{16}$.

Los centros de veraneo de playa más visitados son: San Sebastián, Santander, Gijón, Fuenterrabía (Guipúzcoa), La Coruña, Alicante, Málaga, Sanlúcar de Barrameda (Cádiz), Valencia, etc.

\section{San Sebastián y Santander, dos ejemplos de centros de turismo}

San Sebastián, "La Bella Easo", es la ciudad de mayor prestigio, cuyo cosmopolita Gran Casino, al igual que el de Montecarlo, es conocido en toda Europa y es referente en las crónicas de sociedad sobre el veraneo en los periódicos y revistas gráficas españolas, mientras que Santander, "La Perla del Norte" es la urbe beneficiada por los veraneos regios de Alfonso XIII y María Victoria de Battenberg en el Palacio de la Magdalena que atraen a una selecta clientela. La pugna por el protagonismo entre ambas ciudades fue una constante hasta 1931.

San Sebastián se convierte en el centro de la corte durante la Restauración. Era la capital de España en los meses estivales, el lugar veraniego más importante de España y una versión hispánica de las playas francesas.

La principal atracción de la ciudad era la playa, vinculada a las visitas reales: la llegada de Isabel II en 1845 a La Concha a tomar los baños de ola, Amadeo de Saboya en 1872 a las Arenas de Bilbao, y la iniciativa es continuada por Alfonso XII; se reafirma cuando la Regente Reina María Cristina de Habsburgo y Alfonso XIII la eligen como sede oficial de veraneo y también los políticos españoles acuden cada verano haciendo de la ciudad en palabras de Azorín "el más copioso remanso del parlamentarismo". Junto a la familia real se desplazaban destacados miembros de la aristocracia, políticos, embajadores y familias de la alta burguesía madrileña que daban a la ciudad rango de corte veraniega.

Durante este periodo la ciudad experimentará numerosas mejoras urbanísticas: el

14 PÉREZ ROJAS Francisco Javier, y ALCALDE, José Luis: "Casetas, balnearios y casinos", en $A$ la playa. El mar como forma de la modernidad en la pintura española 1870-1936, Madrid, Fundación cultural Mapfre Vida, 2000, pp. 65-97.

15 Guía del turista. Mondariz-Vigo-Santiago. Madrid, Sucesores de Rivadeneyra, 1912

16 LARRINAGA, Carlos: "Le tourisme thermal dans l'Espagne de la restauration ", TISSOT, Laurent Tisot (dir), en Construction d'une industrie touristique aux $19^{\text {ème }}$ et $20^{\text {ème }}$ siècles. Perspectives internationales, Neuchâtel, Alphil, 2003. 
derribo de murallas, la apertura de avenidas, la edificación de suntuosos hoteles y chalets y la construcción del Gran Casino (1882) ${ }^{17}$, el Palacio de Ayete, la edificación de la Real Casa de Campo de Miramar (1889-1893), el Teatro Victoria Eugenia (1912), el Hotel María Cristina (1912) y del Hotel de Londres -sede de los políticos en vacaciones- ${ }^{18}$.

La oferta de atractivos aumenta: construcción de nuevos hoteles, palacetes al estilo Cottage inglés, empiezan a ofrecer una imagen señorial de la ciudad dotada de un ambiente residencial y español. Frente a quienes continúan yendo a Biarritz, acercarse a San Sebastián es una forma de "españolismo". Además, se utilizan zonas recreativas para practicar el tiro al pichón, el juego de pelota, se organizan conciertos, competiciones de regatas, etc.

En los años de la Gran Guerra la ciudad fue una suerte de refugio y su época dorada se mantuvo hasta la supresión del juego en 1922. El desarrollo de un nuevo puritanismo y la crisis económica van a provocar una inflexión del turismo. La inestabilidad republicana y los conflictos bélicos marcaron el final de esta etapa.

Santander, "La perla del Cantábrico" fue una de las primeras ciudades en promocionar actividades relacionadas con las modas higienistas, ofreciendo las frías aguas de la Bahía del Sardinero, y más adelante, uno de los centros de veraneo burgués. La ciudad poco a poco adquirió un sentido residencial, de temporada y se consolidó como centro de servicios ${ }^{19}$. El Ayuntamiento de Santander decide invertir dentro de sus presupuestos municipales una cantidad dirigida a fomentar una práctica social que va extendiéndose en nuestro país. La estancia de Amadeo de Saboya en el verano de 1872, la presencia de Isabel II y Alfonso XII en 1876 incorpora Santander a las preferencias de la moda, compartiendo con San Sebastián el rango de corte estival, como queda reflejado en las crónicas veraniegas de los diarios y semanales del momento.

Posteriormente en Santander se va a producir una modificación de su estructura económica, basada en un modelo de tipo mercantil, que crea una nueva imagen de la ciudad. Nacen nuevas sociedades, se diseña el ordenamiento de costas, se consolidan los baños flotantes y las estaciones balnearias, se realizan mejoras en el urbanismo con intención de embellecer calles y avenidas. Se logra establecer un flujo de turismo con los viajeros, que llegan en los trenes de recreo procedentes de Castilla.

17 MARTÍNEZ DE VELASCO, Eusebio: "El Gran Casino de San Sebastián”, en La Ilustración Española y Americana, Madrid, 34 (1887), pp. 147.

18 Guía San Julián: Indicador Donostiarra, San Sebastián, Artes Gráficas Merecan, 1927.

19 En la Gaceta de Madrid del 17 de julio de 1847 se publica el primer de anuncio sobre baños de oleaje en Santander y supone, al mismo tiempo, la novedad de realizar una inserción de publicidad con carácter turístico. 


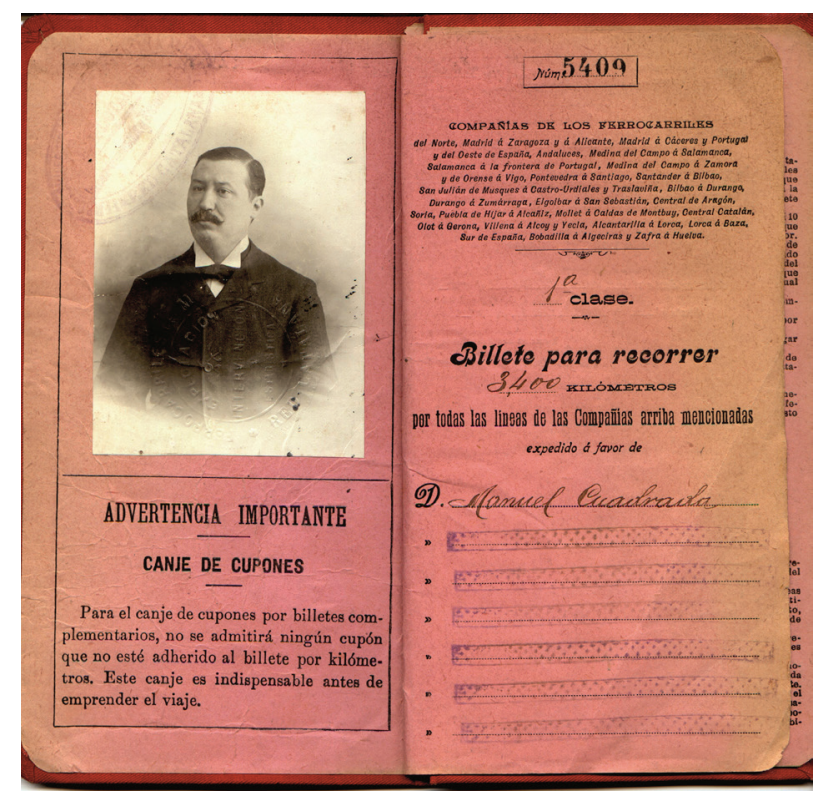

Fig. 2. Billete Kilométrico Tren $1^{\mathrm{a}}$ Clase- Compañías de los Ferrocarriles (sin fecha). Colección particular Juan Carlos González Morales.

Los emprendedores ${ }^{20}$ obtienen del ayuntamiento cesiones de terrenos para edificar casas y chalets, casas de huéspedes, casas de alquiler, fondas, kioscos, cafés. La presencia de escritores como Galdós, Emilia Pardo Bazán, José María de Pereda, etc. le dan un carácter literario.

En Santander, a finales del siglo XIX, la sucesión de varios incendios supuso un punto de incertidumbre para su desarrollo. Las dudas se disipan cuando los hoteles empiezan a florecer y la consolidan como ciudad-balneario. A inicios del siglo XX es una preciosa ciudad comercial, edificada al borde de la bahía y muy visitada por buques de distintos países. La región ya es presentada en las ediciones artísticas de turismo de las guías del veraneante como "la Suiza española" por sus encantadores paisajes para realizar excursiones, sus balnearios y las pinturas rupestres de la cueva de Altamira. En estas primeras décadas se culmina el desarrollo urbanístico ${ }^{21}$.

La Gran Guerra, como en el caso de otras localidades españoles, conllevó un beneficio para Santander al ser refugio de artistas, políticos y personas adineradas ${ }^{22}$. El

20 La figura de la familia Pombo, y en especial Juan Pombo Conejo, alcalde de la ciudad y perteneciente a una de las familias más poderosas, tiene un papel especifico como emprendedores en esta actividad económica. Impulsados por ellos surgieron el Gran Hotel de El sardinero, el primer casino, galerías de baños, los nuevos tranvías, y la apertura de una oficina de información para los forasteros.

21 En 1912 se realiza la entrega del palacio de la Magdalena, y a partir de 1913 los reyes empiezan a frecuentarlo, hasta 1930, durante 17 años. Esta presencia favorecerá la atracción hacia una ciudad que se transforma en Corte de verano, a donde acude el Rey Alfonso XIII y Victoria Eugenia. Son los tiempos conocidos como "los veraneos regios".

22 Las fiestas y actividades están ya centradas en el sport: campo de polo, hípica. La cultura, el ocio y la diversión se diversifican: ferias de Santiago, corridas de toros, semanas deportivas, conciertos y bailes, y en 
impulso turístico se consolidó y brindó la mejor época para la ciudad con la conversión de Santander como destino para el veraneo de la burguesía urbana del interior del país.

La ciudad tuvo unos felices 20 y se reafirmó como núcleo turístico español. Una gran afluencia de visitantes consolidó la creación de nuevas infraestructuras. Con la llegada de la II República, los ya tradicionales veraneos sufren un cambio, al no contarse con la presencia de los monarcas y la crisis económica significó un descenso de la afluencia de las familias burguesas ${ }^{23}$.

\section{Excursionismo, alpinismo y sport}

De entre los modernos modos de viajar, el desplazamiento a pie -por gusto, por placer, por el deseo de ver tierras, de instruirse, realizando al mismo tiempo un ejercicio físico- es una práctica cultural moderna. Poco a poco aumentó el interés por el entorno, se renovó el gusto por la Naturaleza, la preocupación por la conservación del medio natural crece a lo largo de décadas en distintos ámbitos de la sociedad europea, y llegó a ser un elemento de la cultura.

Durante el siglo XIX se constituyeron sociedades geográficas, como La Societé de Géographie de París (1820), también surgen los primeros clubes Alpinos como La Alpevenci (1852) o el Alpine Club británico y núcleos deportivos; ciertas localidades de Suiza, Italia, Alemania, Francia e Inglaterra comienzan a transformarse en auténticos centros deportivos que a nivel local fomentan la práctica del montañismo, la defensa de la naturaleza, el conocimiento de las montañas y la difusión de la cultura.

Una parte de estos sportmen ${ }^{24}$, tras haber pasado por experiencias arriesgadas, bajo el sentimiento de la aventura como necesidad, se transforman en turistas más tradicionales, que practican actividades que favorecen el desarrollo físico y la higiene, de una manera menos peligrosa, más sana y controlada. Las Sociedades deportivas y clubes, comienzan a proliferar en los distintos países europeos, constituyéndose una larga serie de organizaciones en Francia, Suiza, Alemania, Austria o Italia.

presencia de aristócratas y burgueses ricos, que realizan relaciones de promoción social, financiera y política durante el periodo estival.

23 Durante el periodo republicano se propone reorientar el turismo veraniego hacia un turismo cultural a través de la fundación de la Universidad Internacional de verano.

24 PARDO BAZÁN, Emilia: "Sportman, sportmen y sporment", en Obras completas, tomo XXIV (De siglo a siglo, 1896-1901), 1896, pp. 37-41. 


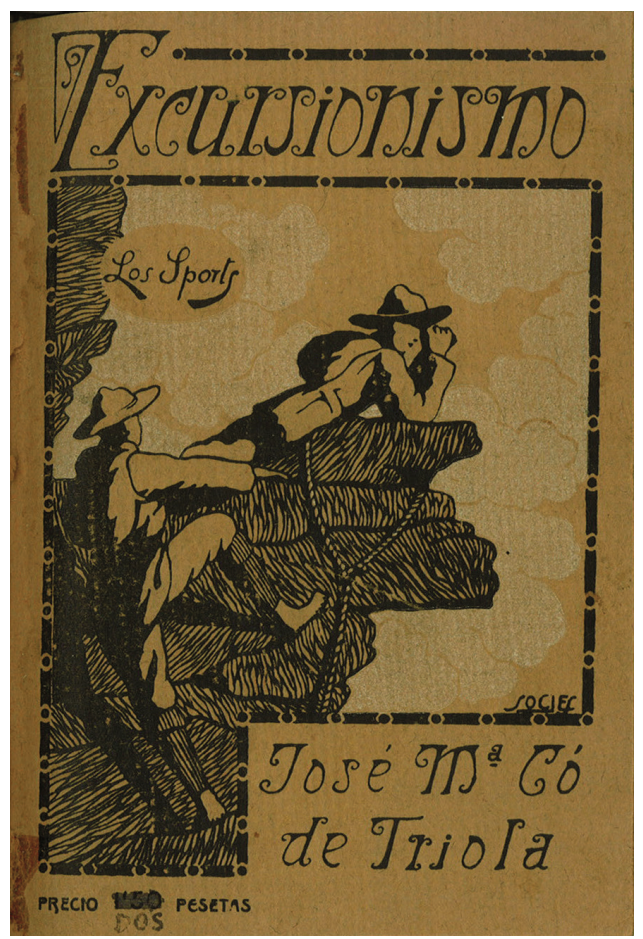

Fig. 3. Excursionismo - Los Sports (Cubierta). Có de Triola, José María. E. Barcelona: libreria Sintes, (sin fecha). Excursiones y excursionistas. Generalidades y consejos. Colección particular Juan Carlos González Morales

Los motivos iniciales de facilitar el ejercicio físico, realizar excursiones, organizar expediciones grupales, que ya presentaban analogías con el turismo, se trocan también en mercantiles. La irrupción de las agencias de viajes y excursiones ofertando en sus programas la placentera práctica de estas actividades hace que adquieran una dimensión turística todavía mayor. El excursionismo, junto al alpinismo y a la práctica del deporte, se convertirá a lo largo del siglo XX, además de en una filosofía de vida, un misticismo - en muchas ocasiones de fin de semana- y en una gran fuente de ingresos.

En España esta práctica se introdujo a través de las influencias krausistas y de la Institución Libre de Enseñanza, cuyos planteamientos reformistas y renovadores formaron parte del programa regeneracionista.

La divulgación de lugares pintorescos situados en los entornos de las ciudades, va extendiéndose, la prensa dedica reportajes, existen revistas especializadas y se redescubren "los encantos" paisajísticos o artísticos de los alrededores de las grandes urbes, nunca sentidos anteriormente bajo esa perspectiva. La afición a los deportes relacionados con la montaña se incorporará a la práctica del ocio en España ${ }^{25}$.

25 E. GONZALVO, Celestino: Apuntes sobre el turismo, Madrid, Edición T.P, 191. 
Los primeros sportmen españoles eran considerados aficionados al turismo. Son seguidores de una práctica, que procede de Europa, y que tiene por objeto el ejercicio corporal al aire libre, las caminatas, ascensiones, oxigenar los pulmones y recrearse. Estos hábitos van infiltrándose en nuestro país a través de las modas procedentes de Inglaterra.

En distintas zonas de la geografía nacional empiezan a constituirse grupos locales, bajo la denominación de sociedades de excursiones que organizan salidas dominicales, programas de actividades y suelen publicar un boletín. Entre las más destacadas:

- Sociedad Española de Excursiones

- Sociedad Castellana de Excursiones

- Associació Catalanista d'Excursions Científicas

- Sociedad de excursionistas de Málaga

- Montañeros de Navarra

- Montañeros de Aragón

- Club Alpino Español

- Los doce amigos / Agrupación Alpinista Peñalara / RSEA

- Sociedades en la Sierra de Gredos (Ávila - Salamanca)

- La Sociedad Gredos-Tormes de Hoyos del Espino

- Sociedad "Sindicato de turismo" (Barco de Ávila)

- Sociedad Arenas-Gredos (Arenas de San Pedro)

- Sociedad Sindicato de Iniciativas, turismo y veraneo de Béjar

- Unión Velocipédica Española

- R.A.C.E. (Real Automóvil Club Español) ${ }^{26}$

- Touring Club $^{27}$

\section{De los viajeros modernos a los turistas contemporáneos: las primeras iniciativas en torno a la industria de los forasteros (1905-1929)}

A inicios del siglo XX una parte de la clase política española y del sector económico formada por políticos liberales, círculos de empresarios de la burguesía progresista, comerciantes con intereses en los negocios de exportación e importación- busca una vía de conexión entre España y Europa, para favorecer sus intereses económicos y políticos, facilitar la instalación en la sociedad española de los pensamientos positivistas de finales del XIX e inicios del XX. El objetivo es que España se incorpore a

\footnotetext{
26 A partir de inicios del siglo XX de crea El Real Automóvil Club Español (RACE), el Real Automóvil Club Catalán (RACC), el Real Motoclub, el Real Automóvil Club de Guipúzcoa, y otras sociedades, constituidas de manera afín a sus homónimas europeas. En estos clubes se agrupan élite aficionada al sport del automovilismo.

27 En febrero de 1905 aparece, al difundirse los medios motorizados y como rama de la Unión Velocipédica española, el Touring Club Hispano-Portugués. Esta sociedad, que toma referencias de sus homónimos existentes en Italia y Francia, creada para el fomento de los viajes por España y Portugal, ofrece a sus asociados ciertas comodidades y facilidades a la hora de emprender un viaje, ofreciéndoles tarjetas de identidad para el paso de las fronteras, insignias, revistas, reducciones sobre guías, mapas, rebajas en hoteles, oferta servicios para la recepción de extranjeros y colabora en la edición de circulares, boletines, impresos y obras relativas a viajes.
} 
la modernidad europea. Se valoran las grandes ventajas económicas que produciría el desarrollo de esta industria y se sopesan las condiciones y posibilidades del turismo español ${ }^{28}$.

El primer periodo de articulación del turismo desde el Estado español comienza en el año 1905, cuando aparece la primera acción legisladora estatal dirigida a los forasteros. A propuesta del Ministro de Fomento, Álvaro de Figueroa, Conde de Romanones, el rey Alfonso XIII firma un Real Decreto por el que se crea una Comisión Nacional encargada de fomentar en España las excursiones artísticas y de recreo del público extranjero. ${ }^{29}$ Con la creación de esta comisión se estableció de manera oficial el inicio de una política turística pública. 1905, además, se convierte en un año de organización turística y de celebración de eventos: se festeja el tricentenario de la publicación de la primera parte de El Quijote, se comienza a publicar la revista $\mathrm{Le}$ touriste, se funda el Touring Club Hispano-Portugués y se constituyen las primeras sociedades - a imitación de las ya existentes en Europa- que fomentan la atracción de forasteros y el desarrollo del turismo ${ }^{30}$.

En los años posteriores continuarán apareciendo nuevas iniciativas:

- 1906: Real orden de 6 de junio de 1906 sobre comisiones especiales en todos los municipios para propagar y fomentar el turismo.

- 1907: Asamblea Nacional de Fondistas y Similares.

- 1908: Primer Congreso Internacional del Turismo y de los Sindicatos de Iniciativa - celebrado durante Exposición Hispano-Francesa de 1908 en Zaragoza-, donde se analiza la situación del turismo en España y a nivel internacional, se elaboran propuestas de promoción del turismo, se acuerda organizar futuros congresos anuales ${ }^{31}$ y la constitución de la Federación Franco-española de Sindicatos de Iniciativa.

- 1909-1911: Real Orden Circular de 1909 que contiene las disposiciones que rigen el funcionamiento de los establecimientos destinados al hospedaje de viajeros y regula las condiciones de los billetes de los medios de transporte.

\footnotetext{
28 "Hace algunos, muy pocos años, la palabra turismo era casi desconocida en nuestra patria. La persona que viajaba por ver, por instruirse y por recrearse, era considerada como un ser excéntrico, que buscaba quizás en los viajes el medio de dilapidar su fortuna. No se llegaba a concebir que hubiese quien, por ver, visitar y admirar unas ruinas, por ejemplo, hiciera un largo viaje, sufriendo las molestias y gastos consiguientes al mismo, y de aquí que eran contadísimos los que disfrutaban las delicias del turista. Nada en realidad se hacía entonces por desterrar estas rancias preocupaciones y por fomentar la afición a los viajes, hasta que en 8 de Febrero del presente año, apareció en esta corte el Touring-Club Hispano-Portugués, Sociedad creada para el fomento de los viajes a España y Portugal. Larga y penosa labor tenía que realizar dicha patriótica Sociedad, labor que si en el extranjero había producido excelentes resultados, era muy dudoso que en España fructificase, dadas las dificultades con que había de tropezar". "Le Touriste", en Revista mensual ilustrada para el fomento de los viajes por España y Portugal, Madrid, año I, 1(1905), p.1.

29 El texto íntegro puede consultarse en la revista digital Historia del Turismo en España, sección Memoria del tiempo, 0 (2009): http://historiadelturismo.es/index.php/archivo.html

30 Ej. la fundación de la sociedad Fomento de Turismo de Mallorca.

31 Son referencia clave para conocer los trabajos de organización del turismo realizados. Se celebraron un total de cinco, que se interrumpieron en 1912 -el último, en Madrid- por el estallido bélico. En el foro de estos congresos, representantes de los distintos sectores españoles, franceses y posteriormente portugueses aúnan esfuerzos en pro del desarrollo y la extensión del turismo internacional.
} 
En el Senado aparecen las primeras proposiciones de ley relacionadas con el sector. Se construyen modernos hoteles en las principales ciudades. Se realizan los primeros estudios españoles de carácter científico sobre el desarrollo del turismo en España. Se abren agencias de viajes y excursiones. Las compañías navieras y las de ferrocarriles se implican en el proyecto. Se crean comisiones para regular el tráfico ferroviario; se extiende la práctica deportiva; se roturan caminos y se señalan cumbres; aumenta el excursionismo, el alpinismo; se publican guías e itinerarios descriptivos para realizar excursiones, revistas, etc. Todo parece encaminarse hacia un glorioso porvenir turístico, pero no será así.

A pesar de este proceso de organización emprendido, los resultados esperados no se alcanzaron: la Comisión Nacional no llegó a constituirse. Frente a los proyectos bien intencionados de futuro, la política española cambia de rumbo y no hay continuidad. La intervención del Estado español en el turismo cambiaba en función del gobierno, mientras la facción liberal buscaba, dentro de su ideología, transformar el sector siguiendo los parámetros europeos y norteamericanos, adaptar el país a nuevos estilos de vida, lavar la imagen negativa de España. Estas nuevas directrices chocan con las de los gobiernos conservadores

En estos años, en realidad, el turismo nunca despertará gran interés ni en los gobiernos ni en las diversas instituciones del Estado. Por una parte, las acciones acometidas fueron puntuales y dependían de las personas a cargo de las carteras ministeriales que otorgaban mayor o menor provisión de fondos para el turismo. Por otra, no existió un apoyo prioritario en las esferas de poder, quedando relegado, repetidas veces, ante otras medidas de mayor alcance patriótico.

Los esfuerzos del sector público para desarrollar la industria turística caen en saco roto, mientras que la iniciativa privada es escasa, no arriesga y no existe coordinación. En España falta un acondicionamiento general de las infraestructuras: fallan las comunicaciones en líneas de ferrocarriles con Europa, se carece de ferrocarriles secundarios, no existen carreteras modernas que faciliten el acceso a las caravanas de turistas que puedan decidirse a visitar España en automóvil, la mayoría de carreteras tienen un firme deficiente, la red hotelera es muy desigual, etc. Asimismo se considera España un país excesivamente caluroso, y existe una mala imagen en el exterior, reforzada por las guías internacionales que aconsejan dar preferencia a otros destinos europeos.

\section{La Comisaría Regia de Turismo y Cultura Artística (1911-1928)}

En junio de 1911 el gobierno liberal presidido por José Canalejas nombró Comisario Regio de Turismo y Cultura Artística a Benigno de la Vega-Inclán y Flaquer, Marqués de la Vega Inclán (1858-1942), cargo que ostentará durante el periodo 1911-1928. La Comisaría Regia emerge como un organismo de ámbito estatal, dependiente de la Presidencia del Consejo de Ministros, para asumir la tarea de divulgación y propaganda turística de España. El Marqués de la Vega-Inclán coordina y dirige la puesta en marcha de las nuevas iniciativas turísticas, culturales y artísticas, a la vez que desarrolla una labor diplomática de representación de España en el exterior. 
La propaganda de la Comisaría Regia del Turismo, procura el desarrollo del turismo y la divulgación de la cultura popular. La nación española se presenta bajo el concepto de la diversidad, se promueve, sobre todo, el turismo cultural -la España artística y monumental-, se presenta nuestro país como un gran museo de antigüedades, a la vez que un espacio de paisajes pintorescos en donde se pueden contemplar hermosas bellezas naturales y practicar excursionismo. Al mismo tiempo se ofrece al visitante la imagen de una animada vida española, llena de fiestas populares y costumbres alegres y variadas.

Las principales iniciativas de la Comisaría Regia durante este periodo fueron:

- Edición de cuidadas publicaciones de carácter artístico, El Arte en España, editadas para generar corrientes de visitantes.

- Labores artísticas, arqueológicas y restauraciones en la Alhambra y el Generalife de Granada; rehabilitación del Barrio de Santa Cruz en Sevilla...

- Creación de museos: Museo y Casa del Greco (Toledo), Casa de Cervantes (Valladolid), Museo Romántico (Madrid). ${ }^{32}$

- Exposición Internacional del Turismo de Londres en 1914 y presencia en las de Nueva York (1922-23) y Filadelfia (1926).

- Creación de albergues, alojamientos y residencias antecedente de la Red de Paradores del Estado, mediante la edificación de Gredos y Mérida.

En las actuaciones de la Comisaría se juntan logros y fracasos, luces y sombras. No puede ser considerada como un organismo coordinador del turismo de gran magnitud, pues su existencia durante estos años está marcada por una escasa asignación presupuestaria. La coordinación y dirección de sus atribuciones fueron llevadas, de una manera casi personal, por el Marqués de la Vega-Inclán, desde una oficina que tuvo varias sedes, donde el Comisario manifestó en repetidas ocasiones la escasez de recursos para procurar el desarrollo del turismo y la divulgación de la cultura artística popular. En el desarrollo de su labor se entremezclaron sus intereses personales como hombre de arte con los de agente comercial. El Marqués estuvo vinculado al hispanista norteamericano Ascher Huntington, fundador de la Hispanic Society y habitual comprador de obras de arte hispanas. Dentro de este círculo también encontramos otros personajes del entorno palaciego, como el monarca Alfonso XIII, Joaquín Sorolla o Manuel B. Cossío.

A partir de 1926 se empezó a cuestionar la eficacia de la ya veterana Comisaría Regia y se consideró la necesidad de reformar las estructuras de los distintos organismos gubernamentales, creándose el Patronato Nacional de Turismo (P.N.T.), ya que la gran corriente turística que fluía por Europa no llegaba hasta nuestro país.

32 Reabierto en el año 2009 con el nombre de Museo del Romanticismo. 


\section{El Patronato Nacional del Turismo (P.N.T.)}

El Patronato Nacional del Turismo es una institución estatal de carácter turístico -y a la par con contenido político-, dependiente de la Presidencia del Consejo de Ministros y creado mediante Real Decreto el 25 abril de 1928, por el Directorio Militar de Primo de Rivera. Su creación supuso una reforma de la política estatal turística realizada hasta esos momentos y extinguió a la Comisaría Regia de Turismo y Cultura Artística.

Las motivos de estos cambios fueron el agotamiento del modelo anterior, los deseos de renovación, el enfrentamiento político de la figura del Marqués de la VegaInclán con algunas fuerzas vivas del país -en concreto con hosteleros catalanes- y la necesidad de obtener mayores frutos de esta industria, que en otros países europeos estaba contribuyendo a la consolidación de las economías. Con la creación de este organismo se buscaba mejorar la organización, disponer de mayor presupuesto y obtener mayores beneficios, crear un moderno equipo de trabajo, favorecer especialmente a la industria hotelera, abrir nuevos centros y agencias de turismo y reforzar la imagen de España en el exterior. El objetivo es preparar a España para el turismo, realizar una labor propagandística, fomentar el turismo interior y atraer el extranjero.

El P.N.T. dispone de un Comité directivo, ejecutivo, delegaciones, subdelegaciones y representaciones locales. En su compleja estructura también existe un Consejo General del Turismo.

La financiación del P.N.T. procede de la implantación de un seguro obligatorio de transportes, de anticipos del tesoro, de la asignación de una partida presupuestaria y cuenta con autorización para realizar empréstitos a empresas. Estos fondos permitirán crear una oficina central, abrir agencias en el exterior, obtener subvenciones para congresos, disponer de un pabellón de turismo en la exposición Iberoamericana de Sevilla, en 1929, establecer un crédito hotelero y diseñar un ambicioso plan de construcción de albergues de carretera, refugios, paradores y hosterías.

\section{Los Congresos de Turismo. Sumar fuerzas, compartir experiencias}

"En el turismo hay un principio, algo esencialmente civilizador"

Miguel de Villanueva, Ministro de Fomento español, durante el discurso oficial de apertura del V Congreso Internacional de Turismo. ${ }^{33}$

La celebración de una serie de congresos de turismo, durante estos primeros años de siglo, muestra los intentos de trabajo conjunto para extender la fuerza del turismo. Se trata de una serie de iniciativas que merece la pena recordar por la labor, los planteamientos y el entusiasmo de sus componentes, y aunque finalmente no llegaron a

33 CRESPO, Hilario: V Congreso Internacional de Turismo de la Federación de los Sindicatos de Iniciativa Franco-Hispano-Portugueses: Memoria General. Madrid, Artes Gráficas Mateu, 1913. pp 44. 
tener los resultados esperados, muestran la búsqueda y el futuro deseado durante la creación de la industria de los forasteros.

\subsection{El Primer Congreso Internacional de Turismo y de los Sindicatos de Iniciativa. Zaragoza (20-23 de noviembre de 1908)}

La idea original de celebrar el Primer Congreso Internacional de Turismo en España procede de la visita realizada por periodistas, fondistas españoles y un grupo de empresarios aragoneses a Burdeos con motivo de la Exposición Marítima y de Productos celebrada en esta localidad durante el verano de 1907. Tomando como punto de referencia el funcionamiento de los sindicatos de iniciativa franceses y su "poder mercantil" se fraguó la idea de realizar un Congreso de Turismo en España.

Basilio Paraíso, médico, empresario y político, logrará que las personalidades locales de Zaragoza, entre ellos el Marqués de Arlanza, formen parte de una comisión gestora encargada de los preparativos del Congreso y creen el Sindicato de Iniciativa de Zaragoza.

El Congreso se celebró en Zaragoza entre los días 20 y 23 de noviembre de 1908, durante la Exposición Hispano-Francesa de ese mismo año. A este congreso acudieron, además de los escasos organismos existentes para el fomento del turismo, representaciones de las sociedades deportivas nacionales, de la industria hotelera, de la prensa -particularmente aquellas publicaciones que se ocupaban del Sport- de Municipios y de Sindicatos y Federaciones de Francia. Cada una de las sesiones del Congreso iban acompañadas de intervenciones de personajes destacados.

Los temas a debatir se estructuran en cuatro secciones:

\section{Sección primera}

- Federación Internacional de los Sindicatos de Iniciativa y comisiones de Atracción de forasteros y del turismo, y relaciones que deben establecerse entre unos y otros.

- Unión interpirenaica con relación a las dos vertientes o faldas de ambos lados del Pirineo y apertura de nuevas vías de intercomunicación mejorando las existentes.

- Constitución y atribuciones de un doble comité domiciliado en Francia y España, titulado "Entente Amicale Franco-espagnole".

- Constitución del sindicato de iniciativas de Aragón.

Sección segunda

- Relaciones entre los sindicatos de Iniciativa y las compañías de navegación, ferrocarriles, touring clubs, federaciones y Asociaciones Fondistas, Sociedades deportivas, agencias, viajes y excursiones.

- Transporte de viajeros, paquetes postales, correos, telégrafos y teléfonos.

- Diferentes medidas sobre confort e higiene moderna en los hoteles, muelles, vapores, ferrocarriles, tranvías, carruajes y salas de espera.

Sección tercera

- Publicidad en general; guías descriptivas y del viajero en diferentes idiomas. Cambio recíproco de guías regionales, con la enumeración de los monumentos históricos, hechos notables, primeras maravillas, reales sitios, estaciones veraniegas e invernales, 
balnearios, climas, mapas, catálogos, montañas, fronteras, desfiladeros y alojamientos de ambos países.

- Guías personales, consulados, intérpretes, aduanas y cambios.

Sección cuarta

- Garajes, automóviles, bicicletas, carreteras y caminos.

Los temas principales de mayor debate fueron la preocupación por los transportes, la vinculación a las compañías de ferrocarriles, navieras y circulación automovilística; la constitución de una federación franco-española de Sindicatos de Iniciativa con la intención de estrechar lazos entre Francia y España, la creación de un "Comité Internacional de acuerdo amistoso Franco-Español" y lograr el compromiso de apoyo por parte de cámaras de comercio, círculos mercantiles y los Sindicatos de Iniciativas que estaban apareciendo en nuestro país.

El Congreso acuerda por unanimidad la creación en el más breve plazo posible de este Comité y que el segundo Congreso se celebre también en España, el año siguiente, en la ciudad de San Sebastián ${ }^{34}$.

\subsection{El Segundo Congreso Internacional de Turismo. San Sebastián (4-7 de oc- tubre de 1909)}

La Comisión Municipal de Fomento del ayuntamiento de San Sebastián constituyó el Sindicato de Iniciativa y Propaganda de S.S., que será el encargado de realizar los preparativos de este II congreso y de remitir invitaciones a todas las entidades que asistieron al anterior congreso y a diversos Sindicatos franceses, dejando abierto el programa de cuestiones a tratar. A este II congreso, asistieron muchos más delegados oficiales, extranjeros y españoles que al primero, y participaron numerosos representantes de la industria hotelera de Francia y España.

En este Congreso se crean cuatro comisiones que estudiarán los temas propuestos a debate: Organización y Trabajos generales, Publicidad y Propaganda, Transportes y Comunicaciones, Asuntos Diversos.

La Comisión de Organización y Trabajos generales es la encargada de examinar las propuestas de los distintas colectivos que remitieron su cuestionario al Congreso: el Sindicato de Arcachón, el Sindicato de Burdeos, la Federación de la Costa de la Plata, el Sindicato de Hendaya, el Comité del Congreso de Hostelería Latina, el Sindicato de San Sebastián, la Asociación de Dueños Fondistas y Similares de Cataluña, la revista El Viajero de Barcelona, la Sociedad de Atracción de Forasteros de Barcelona y el Club Alpino español.

En la sesión de clausura se presentaron los acuerdos finales:

- Organización y trabajos generales: Aplazar la reforma del reglamento del Congreso de Turismo hasta la aprobación de un reglamento definitivo en el siguiente Congreso.

34 Ver YARZA MONTALAR, Enrique: Memoria del I Congreso Internacional del Turismo y de los Sindicatos de Iniciativas celebrado en Zaragoza del 20 al 23 de Noviembre de 1909, Zaragoza, (s/n), 1908 y http:// hemeroteca.abc.es/nav/Navigate.exe/hemeroteca/madrid/abc/1908/11/22/010.html 
- Publicidad y propaganda: Promover la publicidad Franco-Hispano-Portuguesa.

- Transportes y comunicaciones: Establecer que las relaciones con las compañías de transportes sean ejercidas de manera común por Sociedades Turísticas, Sindicatos de Iniciativas, Asociaciones Hosteleras, las Diputaciones Vascongadas, el Touring Club y el Real Automóvil Club de España.

- Asuntos diversos: Gestionar acuerdos con las compañías de ferrocarriles, estudiar medios de comunicación entre los países mediante la creación de rutas, crear en Madrid y París un Comité d'Entente Amicale, solicitar del Ministerio de Hacienda disposiciones fiscales para el funcionamiento de las empresas, aumentar los presupuestos de los Poderes Públicos para la mejora de carreteras, estimular las Sociedades de Turismo y Sport, disposiciones sobre temas fronterizos, desaparición de trabas o restricciones para la visita de monumentos y objetos artísticos, destinar en los muelles lugares para los yates de recreo y embarcaciones de turistas, creación de hoteles modestos pero higiénicos en las regiones montañosas donde se puedan practicar deportes invernales, crear chalets-refugios, celebrar fiestas locales y populares, que el gobierno subvencione a los Sindicatos de Iniciativa y Sociedades de Atracción de Forasteros y demás sociedades dedicadas al fomento del turismo, recurrir a la Casa Baedeker para que corrija la información que presenta sobre España, convocar a los Sindicatos para informarles sobre las actividades de la Federación Pirenaica.

En la sesión de clausura se propusieron diversas opciones de lugares para celebrar el tercer Congreso: Barcelona, Madrid, recordándose el acuerdo de celebrar alternativamente estas Asambleas en España y Francia. Tras un amplio debate se acordó celebrar el tercer Congreso de Turismo en Francia, designándose como sede definitiva la ciudad de Toulouse. Portugal aparece ya como miembro de pleno derecho de la confederación antes de la celebración del tercer congreso.

La comisión organizadora del tercer congreso, recogiendo el relevo del anterior, confirma el nacimiento de esta unión bajo la denominación de Federación de Sindicatos de Iniciativa Franco-Hispano-Portuguesa. El Congreso de Toulouse sella la alianza entre los tres países y deja entrever la intención de continuidad con que querían dotar a la federación.

\subsection{El Tercer Congreso Internacional de Turismo de la Federación de los Sindicatos de Iniciativa Franco-Hispano-Portugueses, Toulouse (10-16 de octubre de 1910)}

A este congreso, celebrado en Toulouse, asistieron 62 congresistas españoles, 31 portugueses, 74 franceses, mas los miembros del comité de organización y como presidentes honorarios cargos políticos franceses. También estuvieron representados a nivel oficial varios ayuntamientos (Madrid, Segovia, Burgos, San Sebastián, Salamanca, Toledo, Ávila y Málaga). En cuanto a los sectores privados hubo representación de Asociaciones de Propaganda, de Fomento del Turismo, Cámaras de Comercio, Sindicatos de Iniciativa, Industria Hotelera, prensa especializada, ferrocarriles, etc. Los congresistas españoles se quejarán durante el congreso de la ausencia de representación de compañías de ferrocarril españolas. A pesar del gran número de asistentes este congreso se encontró con algunos obstáculos que entorpecieron, 
e incluso impidieron la llegada a Toulouse de algunos congresistas: mientras que en Francia se estaba desarrollando una huelga de ferrocarril, en Portugal se estaba viviendo una Revolución ${ }^{35}$.

Se debatió sobre la relación existente entre los hoteles, a nivel estatal e internacional. Se analizó el tráfico de viajeros, la situación de los medios de comunicación y transportes: carreteras, ferrocarriles, automóviles, ciclismo, navegacion, puertos, servicios aduaneros, higiene de los vehículos, estaciones y muelles... Para ello se solicitaron acuerdos entre las compañías de ferrocarril de Francia, España y Portugal, para que tomasen medidas orientadas a mejorar la calidad de los servicios internacionales en los trenes de lujo y en los ordinarios, disminución de los tiempos de trayecto, supresión de posibles trasbordos, establecimiento de billetes de excursiones circulares y directos, creación de una línea directa que, partiendo de Vigo o Cádiz, pasara por Madrid para terminar en Barcelona; puesta en funcionamiento de un rápido tren semanal destinado a que los turistas sudamericanos pudiesen así visitar Portugal, España, el sur de Francia e Italia; coordinar los trenes entre Francia y España con trayectos semanales directos.

Se otorgó un mandato permanente a los Sindicatos de San Sebastián, Madrid, Barcelona, Málaga y Burgos para que se cumplieran los acuerdos alcanzados.

\subsection{El Cuarto Congreso Internacional de Turismo de la Federación de los Sindicatos de Iniciativa Franco-Hispano-Portugués. Lisboa (12-19 de mayo de 1911)}

La candidatura inicial de Lisboa como sede del IV fue largamente discutida en el Congreso de Toulouse. Su candidatura fue aceptada, pero resultó polémica hasta el final. Barcelona deseaba ser la próxima sede y Portugal resultaba un país poco conocido, con poca proyección a nivel europeo, a lo que debemos agregar que su incorporación efectiva a la federación era relativamente reciente; aunque ésta se acordó en San Sebastián (1909), su puesta en práctica hubo de dilatarse prácticamente hasta 1911, ya que en el congreso de Toulouse la delegación de Portugal, debido a las circunstancias políticas, no tuvo apenas representación ${ }^{36}$.

El Congreso tuvo que ser retrasado unos meses sobre la fecha inicialmente proyectada, a causa de la inestabilidad política de Portugal y los numerosos Congresos que tuvieron lugar en Roma, donde se estaba desarrollando una Exposición Universal. El Congreso de Lisboa estuvo marcado por la fuerza y el dinamismo de un país que acababa de salir de una guerra y quería demostrar al mundo su potencial. El apoyo

35 Para informar del tercer congreso disponemos de los testimonios, en forma de memoria, de los concejales Bernardo Martín y González y Leandro Gómez de Cadiñamos, representantes respectivamente de los ayuntamientos de Madrid y Burgos. MARTÍN Y GONZÁLEZ, Bernardo. Tercer Congreso Internacional de Turismo celebrado en Toulouse (Francia) en los dias 10 al 16 de Octubre de 1910: Memoria presentada al Excmo. Ayuntamiento de Madrid por el concejal D. Bernardo Martín y González. Madrid, imprenta municipal, 1910.

36 Portugal a nivel interno está en proceso de organizarse políticamente. El gobierno era provisional -no olvidemos que estaba aún en vías de constitución, pues acababan de superar una revolución- y mucha gente estaba en desacuerdo con la idea de organizar este congreso, pues pensaban que no era el momento oportuno, pero a la postre se apostó valientemente por mantener su candidatura a pesar de los acontecimientos políticos. 
gubernamental y de los sectores privados a los congresistas es fácilmente perceptible al conocer las ayudas económicas de las que disfrutaron los congresistas y el impresionante programa de actividades que se desarrollaron, tanto en sesiones de trabajo como en actividades lúdicas.

Este encuentro gozó de una amplia representación oficial de los tres países. El número de congresistas asistentes fue enorme: 1475 personas (552 mujeres y 932 hombres). Todos los participantes formaban parte de la Gran Comisión, pero como en casos anteriores hubo una Comisión Organizadora, una Presidencia de Honor, un Comité Ejecutivo y seis Secciones diferentes. La Comisión Organizadora de Lisboa debatió ampliamente los temas que previamente recibió para ser tratados en el Congreso, los tradujo a los tres idiomas y seleccionó las memorias enviadas por los congresistas.

Todas las intervenciones se organizaron temáticamente en seis secciones:

I. Comunicaciones y transportes,

II. Hoteles,

III. Sindicatos de iniciativa y propaganda,

IV. Excursiones y estancias en villas,

V. Publicidad,

VI. Cuestiones generales.

Principales acuerdos:

- La creación de una oficina de Turismo en Lisboa.

- Constitución de un consejo superior de turismo.

- Adopción de la hora del meridiano de Greenwich, con objeto de pertenecer a la misma franja horaria.

- Publicación por parte del gobierno portugués de una ley para la protección y organización de los monumentos y servicios artísticos y arqueológicos.

- Discusión de un proyecto de ley sobre la reglamentación de juegos.

- Establecimiento de los estatutos de la Federación Franco-Hispano-Portuguesa.

- Instalación del comité permanente internacional de turismo en Madrid.

- Apoyo material y moral a los Sindicatos de Iniciativa para los que se piensan como recursos los siguientes:

- En el país donde el juego este reglamentado y tasado, sería deseable que los fondos obtenidos de los beneficios correspondientes sean destinados a subvencionar anualmente a los sindicatos de iniciativa, destinando los fondos a premios para animar a celebrar fiestas tradicionales, carreras y deportes varios, etc.

- Creación de "kurtaxe" en el país donde no exista. Este impuesto municipal aplicable a los viajeros que se hospeden en hoteles, debería en un porcentaje destinarse en favor de los sindicatos para hacer frente a los gastos de publicidad.

- Se solicitan subvenciones anuales para los consejos anuales y municipales de cada país que deberían prestar un apoyo muy efectivo para la publicidad de los sindicatos en el extranjero.

- Promoción del turismo colonial y las excursiones escolares internacionales. 
- Organización de un comisariado regio de turismo en España, y nominación del Marqués de la Vega Inclán como Comisario Regio de Turismo.

- Instalación de una oficina central permanente Franco-Hispano-Portuguesa de sindicatos de iniciativa y propaganda en Madrid. Instalación del comité permanente internacional de turismo en Madrid, creado por los estatutos de la federación y cuya primera sesión tuvo lugar en San Sebastián el 8 de octubre de 1911.

- Publicación por parte de los sindicatos de iniciativa españoles y franceses de un álbum de lujo con el título de "Viajes por España".

\subsection{EI Quinto Congreso Internacional de Turismo de la Federación de los Sindicatos de Iniciativas Franco-Hispano-Portugués. Madrid, 24-30 de octubre de 1912}

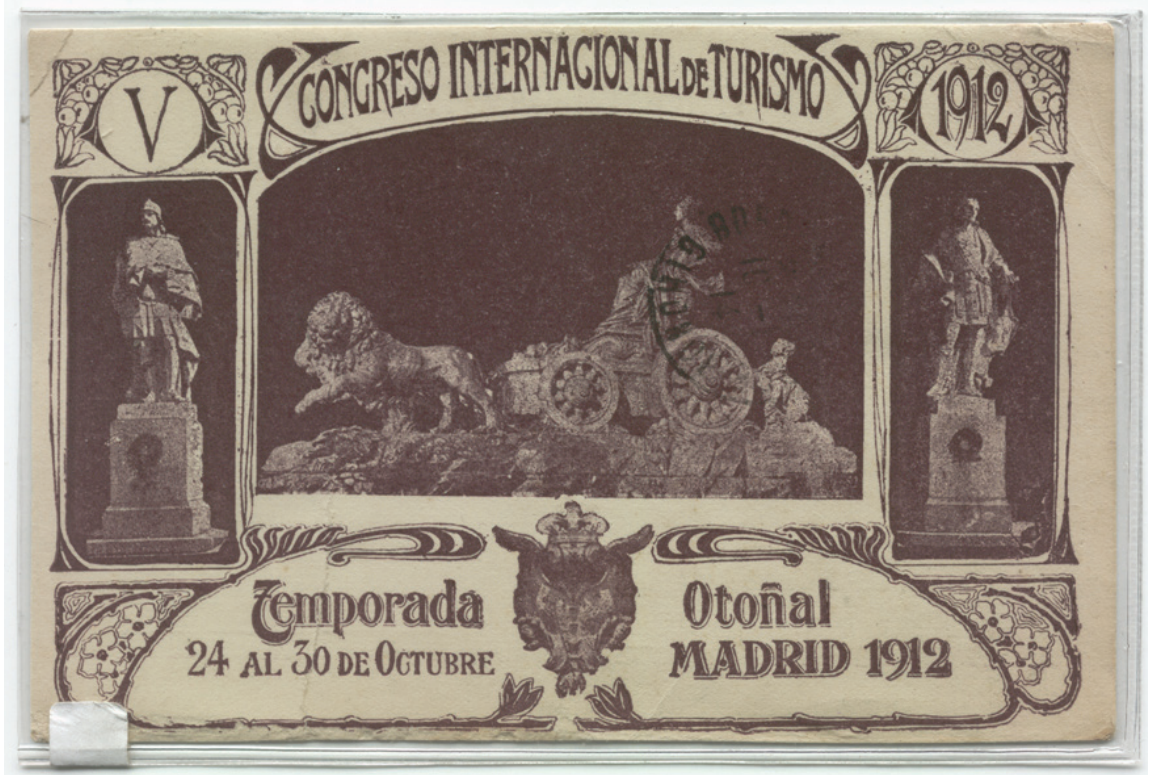

Fig. 4. V Congreso Internacional de Turismo. Temporada Otoñal, 24 al 30 de octubre. Madrid, 1912. Tarjeta Postal conmemorativa. Unión Postale Universelle España. Colección particular Juan Carlos González Morales.

Tras la elección -incluida polémica- de Lisboa como sede del IV Congreso, se acordó que Barcelona, la otra ciudad sólida candidata a ocupar su puesto, fuese la sede del siguiente. Sin embargo, en la Asamblea Nacional del IV Congreso, con la aprobación del Comité Ejecutivo de la Federación Franco-Hispano-Portuguesa, se decidió en último momento que fuese Madrid la sede del quinto Congreso, confiándose a la Asociación de Propaganda de esta ciudad su organización bajo el patronato de S.M. el Rey (Q.D.G.) durante el gobierno de José Canalejas y organizado por la Asociación de Propaganda de Madrid.

Entre los motivos para fijar la fecha del congreso se encuentra el objetivo de iniciar una nueva corriente de turismo durante la temporada otoñal dirigida a España y con- 
cretamente a la capital; mientras a otras ciudades europeas van llegando las lluvias, el frío y la oscuridad, la ciudad de Madrid sigue luminosa, con clima templado y agradable.

En los preparativos se llegó a acuerdos con las principales compañías de ferrocarriles para establecer precios reducidos en favor de los congresistas. Al mismo tiempo se solicitaron subvenciones del estado español y del ayuntamiento de Madrid, y ayudas económicas a sociedades, entidades comerciales e industriales y particulares. Se eviaron circulares de invitación entre los países. Los periódicos y revistas nacionales y extranjeros recogieron ampliamente las noticias del Congreso.

A Madrid asistieron un total de 1124 congresistas (429 señoras y 695 caballeros), divididos por nacionalidades en 76 portugueses, 192 franceses, 2 ingleses, el resto eran españoles ${ }^{37}$.

Como en casos anteriores, la Asociación de Propaganda de Madrid, tras remitir impresos para las proposiciones, memorias y trabajos que habían de ser estudiados, elaboró un programa de sesiones que planteaba los temas de debate en seis secciones y ofrecía un amplio calendario de visitas, excursiones, conciertos, festivales, fiestas, etc.

Las secciones se dividieron del siguiente modo:

\section{Comunicaciones y transportes}

- Ferrocarriles: Servicios directos entre Lisboa y Madrid. Lisboa y Sevilla; trenes de acceso a la Península, reforma de las tarifas de transportes de viajeros, facilidades y ventajas que deberán ofrecerse a los turistas americanos que desembarquen en puertos de la Península.

37 Entre los miembros que formaron la Comisión de Honor cabe destacar: El Rey Alfonso XIII como Presidente de Honor y el Presidente del Consejo de Ministros José Canalejas, como Presidente de la comisión de Honor, asimismo fueron miembros de la misma los Ministros de Fomento, de Estado, de Instrucción Pública, de Portugal, de Brasil, de Argentina y de Méjico; otras personalidades de la vida pública: el alcalde de Madrid, el Gobernador Civil, el Director General de Obras Públicas; y por último representantes de distintos sectores como Basilio Paraíso (Presidente del I Congreso de Turismo), Ms. Guenot (Presidente del III Congreso), Bernardino Machado (Presidente del IV Congreso), D. Torcuato Luca de Tena, Edmond Lorieux (director de la Oficina Nacional de Turismo de Francia), Mariano Rubio (Presidente de la Sociedad de Atracción de Forasteros) y los presidentes de los Sindicatos de Iniciativa de Aragón, San Sebastián, Burgos, Málaga, Grenoble, El Conde de Peñalver (Presidente del R.A.C.E.) y El Marqués de Marianao (Presidente del R.A.C. de Cataluña) y los presidentes del R.A.C. de Andalucía, Guipúzcoa, Asturias, Valencia y del Montañés. Félix Boix (Director de la Compañía de Hierro del Norte) y los directores de las compañías de ferrocarriles de Madrid a Zaragoza y a Alicante, de la Compañía de Ferrocarriles de Madrid - Cáceres - Portugal, de la Compañía de Ferrocarriles Andaluces y de la Compañía de Ferrocarriles de Salamanca a la frontera de Portugal entre otros. La comisión organizadora estuvo formada por el Marqués de la Vega Inclán (Diputado en Cortes y Comisario Regio) y El Conde de Peñalver (Alcalde de Madrid, presidente del R.A.C.E. y de la A.P.M.) como presidentes; Francisco García Molinas (Senador, Primer teniente de Alcalde y Vicepresidente de la A.P.M.), Carlos Prats (Senador y Presidente de la Cámara de Comercio), Emilio Zurano (Presidente del Circulo de la Unión Mercantil) como Vicepresidentes; Hilario Crespo como Secretario General; León Rollín como vicesecretario; Eleuterio Martínez como Tesorero; Bernardo Martín como contador; y destaquemos de entre los vocales a Juan Pedro Capdevielle, Vicente Castro Les, Carlos Resines, así como representantes de las Cámaras de Comercio, Cámaras de Industria, Centros Mercantiles, Asociaciones de Fondistas, etc. Por distintas razones estarán ausentes algunas personas que forman parte de la mesa del Congreso, como el Conde de Peñalver (Alcalde de Madrid, presidente del R.A.C.E. y de la A.P.M.) y el Marqués de la Vega Inclán (Diputado en Cortes y Comisario Regio de Turismo y Cultura Artística). 
- Aduanas: Simplificación de las formalidades en las fronteras terrestres y marítimas, conveniencia del establecimiento de Aduanas en las estaciones de Madrid con el fin de evitar el riesgo de equipajes en las fronteras de la Península a los viajeros que hagan su viaje directamente a esta Corte.

- Automovilismo: Ruta de los Pirineos: Los trazados francés, español y las comunicaciones interpirenaicas; circuitos turísticos; puntos de contacto en Francia y Portugal.

\section{Publicidad}

- Publicidad colectiva entre los Sindicatos de Iniciativas, Compañías de ferrocarriles, Hoteles, Establecimientos termales y balnearios.

- Exención de los derechos de Aduanas entre Francia, España y Portugal para las publicaciones de propaganda (folletos, carteles, tarjetas, etc.)

- Transporte gratuito de las publicaciones de propaganda por las Compañías de ferrocarriles de España, Francia y Portugal.

- Organización de los centros de Información de turismo en América del Sur.

- Edición de un álbum monumental que abarque Pirineos franceses, Portugal y España.

III. Sociedad para el fomento del turismo

- Relaciones y acción común entre las Sociedades de la cuenca del Pirineo francés, Portugal y España. (Federación Franco-Hispano-Portuguesa).

- Intercambio de propaganda.

IV. Arquitectura y Turismo

Grupo A. Discusión de temas relacionados con la materia objeto de la sección.

- Medidas para conservar o acentuar el carácter de las ciudades artísticas, si se juzga conveniente.

- Los edificios que utiliza el Turismo o que contribuyen a la atracción de los forasteros, ¿deben caracterizarse por su estilo esencial moderno o inspirarse en los estilos tradicionales del país?

- Medidas más urgentes y de carácter general que los Municipios pudieran llevar rápidamente a las Ordenanzas Municipales para embellecer las ciudades y hacerlas atractivas.

- Medidas más apremiantes y realizables que los Municipios pudieran llevar en breve tiempo a la práctica para mejorar la salubridad e higiene de las poblaciones.

- Disposiciones prácticas que habrán de dictarse para defensa de los paisajes, puntos de vista y para corregir los abusos del anuncio.

- Climatología del Pirineo francés y de la Península Ibérica (mar, llanuras, montañas), los estilos de arquitectura rural y los sistemas y materiales de construcción.

- Geografía monumental y los itinerarios del turismo.

- Conservación de los monumentos arquitectónicos y la riqueza artística como medio de atraer turismo. Catalogación y defensa de este patrimonio.

- Publicación de pequeñas Guías monumentales. Manera de difundir el conocimiento de las bellezas arquitectónicas.

Grupo B. Exposición de proyectos de edificios que el Turismo utiliza y que contribuyen a la atracción del forastero.

- Edificios destinados al albergue de viajeros (hoteles, fondas, mesones, paradores, posadas, hostelerías, casas de dormir, etc.) 
- Edificios destinados al recreo y agrado de los forasteros a los deportes y campos de juego (casinos, kursaales, salas de baile, de reunión, de proyecciones, autódromos, aeródromos, hipódromos, velódromos, plazas de toros, frontones, circos, teatros, embarcaderos, clubes de regatas, campos y pabellones de tiro de pichón, golf, hockey, tenis, polo, foot-ball, etc.).

Grupo C. Concursos.

- Concursos de fotografía, edificios artísticos, ruinas monumentales, paisajes, tipos populares de las diversas regiones del Pirineo francés, España y Portugal; fiestas regionales (la lista de premios se dará a conocer al mismo tiempo que el Reglamento).

- Concursos de catálogos monumentales.

V. Hoteles

- Conveniencia de la creación de una Cámara Oficial Hotelera (tema español).

- Contrato de trabajo. Propinas.

- Escuelas profesionales.

- Relaciones de las Sociedades para el fomento del turismo con las Asociaciones hoteleras.

VI. Cuestiones de interés general

- Deportes de invierno.

- Legislación acerca del turismo.

- Estadística.

- Desenvolvimiento de las industrias termales y balnearias. Enseñanza de la hidrología.

Las sesiones del Congreso se celebraron en el Paraninfo de la Universidad Central de Madrid. Por su aportación o novedad destacamos las siguientes:

- Comunicaciones y Transportes. El R.A.C.E. propuso que el gobierno español gestionase la reparación de carreteras para obtener los grandes beneficios que ofrecía el creciente movimiento de turistas automovilistas extranjeros.

Publicidad. Se solicitó al gobierno que concediera una franquicia postal para los sindicatos de turismo y que por cuenta del Estado se hicieran colecciones de clichés y películas cinematográficas de las ciudades y lugares con monumentos y paisajes de importancia turística, y que estas colecciones se pusieran a disposición de los sindicatos y sociedades para su proyección, tanto en España como en el extranjero.

- Sociedades para el Fomento del Turismo. Se planteó que la Federación Franco-Hispano-Portuguesa debía existir de hecho, y no solo de nombre, y se propuso la creación de Juntas Locales, Juntas Provinciales, Comités Regionales, Comités Nacionales y un Comité Ejecutivo Internacional de la federación.

- Arquitectura y turismo. Se aprobó solicitar normas para la conservación y restauración de los monumentos arquitectónicos y artísticos. Se solicitó impedir la exportación de obras de arte y proceder a la catalogación y defensa de este patrimonio como medio para atraer el turismo.

- Hoteles. Se proyectó la creación de una Cámara oficial de hospedería española.

Otras cuestiones de interés general: el turismo como protector del árbol, el esperanto y el turismo, el turismo y el juego, etc. 


\section{Conclusiones principales:}

- Se solicita que se establezcan billetes de ida y vuelta entre Madrid y todas las poblaciones de la Península (tercera conclusión de la sección primera. Comunicaciones y Transportes).

- Se reclama que las publicaciones y carteles editados por los Sindicatos de Iniciativas o Asociaciones destinados al fomento del turismo estén exentos de tributos y que las Compañías de ferrocarriles los transporten gratuitamente; el gobierno también debería colaborar en este asunto aplicándoles una tasa similar a los periódicos. (Sección segunda. Publicidad).

- Creación de una Comisión permanente de Publicidad.

- Incorporación de la Asociación de Propietarios de Balnearios y de Aguas Mineromedicinales de España.

- Se proponen intercambios escolares por medio de correspondencia y que los colegiales escriban sobre temas turísticos creando premios literarios.

- Se aprueba que cada Sindicato edite un libro-guía, para regalar a los turistas y que colaboren en las mejoras de sus localidades, regiones y federaciones.

Enumeración de propuestas sobre conservación de ciudades artísticas, tesoro artístico, y de los edificios de carácter regional para el embellecimiento de las ciudades.

- Necesidad de mejora de los servicios de higiene urbana.

- Aprobación de reglas sobre el funcionamiento, publicidad, clasificación de hoteles, relación de las habitaciones, servicios disponibles y precios.

- Exigir al editor de las Guías Baedeker rectificaciones sobre los comentarios negativos en sus publicaciones sobre España.

- Convocatoria en Toledo de una exposición de carácter internacional sobre El Greco, con motivo del tercer centenario de su muerte.

- Editar guías de calidad sobre España en varios idiomas.

- Celebración del VI Congreso en la ciudad de Biarritz.

La sesión oficial de clausura del Congreso de Madrid tuvo lugar el día 30 de octubre de 1912 en el Paraninfo de la Universidad Central y fue cerrada por las palabras del Presidente del Consejo de Ministros español José Canalejas:

Iremos al Congreso de Biarritz y no solamente para ocupar un asiento entre vosotros [...] estamos decididos a establecer en nuestra legislación todo género de medidas para dar impulso al turismo; y a la Federación Franco-Hispano-Portuguesa les seremos deudores todos del progreso del turismo y de los lazos íntimos entre las tres naciones. [...] Estamos decididos a establecer en nuestra legislación todo tipo de medidas para dar impulso al turismo; y a la Federación Franco-Hispano-Portuguesa les seremos deudores todos del progreso del turismo y de los lazos íntimos entre las tres naciones [...] En nombre de S.M. el Rey Alfonso XIII, declaro clausurado el V Congreso Internacional de Turismo [Grandes y prolongados aplausos] 3839.

\footnotetext{
38 CRESPO, Hilario. V Congreso Internacional de Turismo de la Federación de los Sindicatos de Iniciativa Franco-Hispano-Portugueses: Memoria General, Madrid, Artes Gráficas Mateu, 1913. pp 295-296.

39 José Canalejas y Méndez, Presidente del Consejo de Ministros, prestó en este congreso uno de sus últimos servicios al país. Días después Canalejas fue asesinado, el 12 de noviembre de 1912 en la Puerta del Sol de Madrid.
} 
El VI Congreso no se celebraría en Biarritz, tal como se había acordado, ni en ninguna otra parte, a consecuencia del estallido de la Gran Guerra, que cerraría esta serie de cinco congresos. Años después se retomaría este tipo de congresos pero ya con otro espíritu. El turismo ya está mucho más mercantilizado y se han puesto en funcionamiento organismos internacionales, como la Sociedad de Naciones, que en sus sesiones abordan el tema del turismo y la sociedad. Pero los protagonistas son ya otros.

\section{Conclusión final}

Se abrieron caminos. Se buscaron fórmulas. Se pusieron ánimos, ganas, intereses económicos, culturales, políticos, personales y profesionales. Sin embargo, el arranque de esta industria española fue demasiado lento, tímido, con escasos apoyos públicos y privados. Se buscó el mejor camino pero no se encontró el más rápido. Se plantearon ambiciosos objetivos que no se alcanzaron.

Habría que esperar a décadas posteriores para obtener los resultados perseguidos y esperados. En cualquier caso, este artículo pretende rendir homenaje a los pioneros, a los primeros y a tantas personas, hoy anónimas, que buscaron y ayudaron a construir la industria de los forasteros.

\section{Bibliografía de referencia y fuentes históricas}

ALBAREDA, Antonio: El Turismo en España, Barcelona, (s/n), (s/d)

ASÚA Y CAMPOS, Miguel: Por carretera: apuntes de viaje desde Madrid a Santander, cruzando las provincias de Segovia, Ávila, Valladolid y Palencia. Madrid, Imprenta del Depósito de la Guerra, 1900.

BIBLIOTECA VASCA F. DE ABRISQUETA. Segundo Congreso de Turismo: celebrado en San Sebastián en los días 4 al 7 de Octubre de 1909, San Sebastián, Sociedad Española de Papelería, 1909.

CALDERÓ, Xavier: El problema del turismo. Contribución a la formación de una política turística en España, Barcelona, Tipografía Emporium, 1932.

CANTÓ, Antonio: Turismo en la provincia de Madrid, Madrid, Imprenta Alpha, 1928. CLUB ALPINO ESPAÑOL: España centro del mundo. Prats, Antonio (fotos y prólogo), Jiménez, Ernesto (texto y proyectos), Madrid, Magisterio español, 1917, tomo I. CLUB ALPINO ESPAÑOL. Anuario 1929/30, Madrid, Talleres Voluntad, 1930.

COMITÉ CENTRAL DE LA UNIÓN VELOCIPÉDICA. Anuario de la Unión Velocipédica Española (1897), Madrid, E. Teodoro, 1897.

COMPAÑÍA TRANSATLÁNTICA. Libro de información para pasajeros: Vapores, correos españoles, $1^{\mathrm{a}} \mathrm{ed}$. Barcelona, Imprenta Siglo XX, 1908.

COMPAÑÍA TRANSATLÁNTICA. Libro de información: tarifas e itinerarios. Información comercial y de turismo, Barcelona, Talleres Tipográficos y de Encuadernación Dalmau, Yuste y Bis, 1920.

CRESPO, Hilario: V Congreso Internacional de Turismo de la Federación de los Sindicatos de Iniciativa Franco-Hispano-Portugueses: Memoria General, Madrid, Ar- 
tes Gráficas Mateu, 1913.

FERNANDES, Luis: IV Congrès International de Tourisme: Lisbonne, 1911, Compte Rendu Général, Lisbonne, (s/n), 1911.

HERRERO ANGUITA, José: Estudio del turismo y proyecto para su desarrollo en España, mediante la creación de un Consejo Nacional y constitución de la campaña Hispanoamericana de Turismo, Barcelona, (s/n), 1926.

IV Congres Internacional de Tourisme-Libonne. 1911. 12-19 MAI Propositions présentées au Congrés. Lisbone, Librerie Feriu, 1911.

MARTÍN Y GONZÁLEZ, Bernardo: Tercer Congreso Internacional de Turismo celebrado en Toulouse (Francia) en los días 10 al 16 de Octubre de 1910: Memoria presentada al Excmo. Ayuntamiento de Madrid por el concejal D. Bernardo Martín y González, Madrid, imprenta municipal, 1910.

MORENO GARRIDO, Ana. Historia del Turismo en España en el siglo XX. Madrid, Síntesis, 2007.

PAMPLONA ESCUDERO, Rafael, y otros: Libro de oro de la Exposición HispanoFrancesa de 1908, Zaragoza, Imprenta y fotograbado del Heraldo de Aragón, 1911. PATRONATO NACIONAL DEL TURISMO. Memoria de los trabajos realizados por el Patronato Nacional del Turismo, desde junio de 1928 al 31 de diciembre de 1929, Madrid, Talleres Voluntad, 1930.

PATRONATO NACIONAL DEL TURISMO. Memoria: correspondiente a la liquidación, revisión y transformación del Patronato Nacional del Turismo, ordenada por el gobierno provisional de la República en su decreto de 23 de abril de 1931: anejos de la memoria, Madrid, Talleres Voluntad, 1931.

SAMA, Salvador (Marqués de Marianao): Consideraciones acerca de la necesidad del fomento del turismo como fuente de riqueza nacional mediante la formación del gran circuito español, Barcelona, Imprenta de Juan Vidal, 1910.

SÁNCHEZ CANTÓN, Francisco Javier: España por F.J. Sánchez Cantón. Patronato Nacional del Turismo, Madrid, Editorial Hauser y Menet, (s/d).

SÁNCHEZ CANTÓN, F.J.: España: divulgación y propaganda, Madrid, Comisaría Regia del Turismo y Cultura Artística, 1925.

VEGA INCLÁN, Marqués de la: Notas sobre turismo Hispano-Americano: dedicadas al primer congreso nacional del comercio español en ultramar, Barcelona, Madrid, Sevilla: Presidencia del Consejo de Ministros, Comisaría Regia del Turismo y Cultura Artística, 1923.

VEGA-INCLÁN, Marqués de la: Turismo en España, Madrid, (s/n), 1927.

VEGA-INCLÁN, Marqués de la: Hospederías y alojamientos populares, Madrid, $(\mathrm{s} / \mathrm{n}), 1928$.

VEGA-INCLÁN, Marqués de la: Solicitud y proyecto realizado para el progresivo desarrollo y organización de Turismo nacional que el Comisario Regio, Marqués de la Vega-Inclán, somete al Gobierno de S. M, Madrid, Comisaría Regia del Turismo, ( $\mathrm{s} / \mathrm{d})$.

YARZA MONTALAR, Enrique: Memoria del I Congreso Internacional del Turismo $y$ de los Sindicatos de Iniciativas celebrado en Zaragoza del 20 al 23 de Noviembre de 1909, Zaragoza (s/n), 1908. 


\subsection{Artículos de la época}

ABRANTES, Duque de: "Causas de la fundación del Touring Club Español”, en Touring Club, revista mensual, octubre de 1930, año I, núm. 1, pp. 2-4.

ALTAMIRA, Rafael: "Viajes por España", en La Ilustración Española y Americana, 15 de octubre de 1896, núm. XXXVIII, pp. 214-215.

ALREDEDOR DEL MUNDO: "El automóvil sustituyendo al tren", en Alrededor del mundo, 20 de febrero 1922, núm. 1183.

BECERRO DE BENGOA, Ricardo: "Por ambos mundos", sección de La Ilustración Española, agosto 1892, año XXXVI, núm. XXI, pp. 114-115.

BELLO, Luis: "España para el turista: Industria de los pintoresco", en Nuevo Mundo, Periódico ilustrado, Madrid, 5 de Octubre, 1905, núm. 613.

CARIVIELA, Eduardo: “QQué son los Sindicatos de Iniciativa y Propaganda?”, en Aragón, Noviembre 1925, Pág. 18.

DELGADO, F. de A.: "Excursión Madrid-París: diario de un turista", en La Ilustración Española y Americana, 30 de Mayo 1903, núm. XX, pp. 326-330.

LA ÉPOCA: "El turismo en España", en La época, 6 de octubre, 1905, año LVII, núm. 18.839. Edición de tarde.

LA ÉPOCA: "La industria del turismo", en La época, 7 de octubre de 1905, año LVII, núm. 19.840. Edición de tarde.

LAFFITTE, Alfredo: "El turismo y los Sindicatos de Iniciativa", en El Pueblo Vasco, 2 de noviembre de 1908.

GARCILASO, Fermín: "Turismo de ambos mundos", en La Ilustración de España y América, 22 de Febrero 1916, núm. 7.

M. DE SEGARRA, Ramón: "Momento actual del turismo español. Su Patronato, las Atracciones de Forasteros y el V Congreso Internacional de Turismo". En Viajes por España, Madrid, 1930, año 3, núm. 7.

MUNOZ, Isidoro: Riquezas Patrias (1918), Institución Gran Duque de Alba y Ayuntamiento del Barco del Ávila, 1990, edición facsímil.

NUEVO MUNDO: "La Exposición de Santander", en Nuevo mundo, apartado "Crónica de la semana". 7 de diciembre, 1905, año XII, núm. 609.

NUEVO MUNDO: "Playas portuguesas", en Nuevo mundo, Jueves 15 de junio, 1905, año XII, núm. 597.

NUEVO MUNDO: "El turismo en España. Una idea patriótica", en Nuevo mundo, 24 de noviembre, 1910, núm. 881.

PARAÍSO, Basilio: Memoria, notas, apuntes y documentos de la labor realizada por Basilio Paraíso, representante de los intereses del comercio en el Consejo Superior Ferroviario, Abril a julio de 1922. Madrid, Sucesores de Rivadeneyra, 1922.

PARDO BAZÁN, Emilia: «Sportman, sportmen y “sporment”». En Obras completas, 1896, Tomo XXIV (De siglo a siglo, 1896-1901), pp. 37-41.

PARDO BAZÁN, E.: "Desde el tren". En Por la Europa Católica, (s/d), núm. 37, pp. $10-16$.

SAMÁ, Salvador (Marqués de Marianao): Consideraciones acerca de la necesidad del fomento del turismo como fuente de riqueza nacional mediante la formación del gran circuito español, Barcelona, Imprenta de Juan Vidal Hnos., 1910. 
SÁNCHEZ CANTÓN, Francisco Javier: «El "viaje de España” y el arte español: Centenario de Don Antonio Ponz», en Revista de Occidente, abril, mayo, junio 1925, Tomo VIII, núm. 24, pp. 307-329.

SANTANDER. La exposición de Artes e Industrias, 20 de agosto, 1905, núm. 1.

SOCIEDAD DE ATRACCIÓN DE FORASTEROS. "Memoria de la I Conferencia Nacional de Turismo". En Barcelona-Atracción, abril 1923, núm. 144, año XIII.

SOCIEDAD DE ATRACCIÓN DE FORASTEROS. Barcelona, Barcelona, Compañía española de artes gráficas, $(\mathrm{s} / \mathrm{d})$

VIDAL, Fabián: "España, país pintoresco", en La correspondencia de España, 1 de junio, 1909, núm 18738.

VIAJES POR ESPAÑA. "Las exposiciones de Barcelona y Sevilla". Madrid, Imprenta Prensa Nueva, enero 1929, año III.

NUEVO MUNDO. "El turismo en España. Una idea patriótica", en Nuevo Mundo, 24 de noviembre, 1910, núm. 881.

EL NORTE DE CASTILLA. "El Fomento del turismo. La Asamblea de hosteleros: lo que dice el Comisario regio. Entrevista", en El Norte de Castilla: diario independiente de Valladolid. 8 de septiembre, 1912, Año 58, núm. 21.249.

\subsection{Guías-Catálogos}

Catálogo de la selección de Arte retrospectivo de la exposición Hispano-Francesa, Zaragoza, Tipografía de Emilio Casañal, 1908.

Catálogo-guía oficial de la exposición Hispano-Francesa, Madrid, Imprenta Alemana, 1908.

Espagne et Portugal. Manuel du voyageur. Baedeker, Karl, $3^{\mathrm{a}}$ edición. Leipzig, Karl Baedeker, 1920 (revisada en 1915).

Espagne et Portugal. Dir. Marcel Monmarché. Hachette. Les Guides Bleus. Direction. París, 1916.

Espagne. Dir. Marcel Monmarché. Hachette. Les Guides Bleus. Direction. París-Londres. 1927.

Guía del Centenario del Quijote, 1905. Madrid, Imprenta Alemana, 1905.

Guía Oficial autorizada por el Excelentísimo Ayuntamiento con motivo de la visita del Presidente de la República francesa Mr. Loubet, a esta Villa y Corte, en Octubre de 1905, Madrid, Imprenta Alemana, 1905.

Guía Ilustrada del Tourista en Cádiz: 1906, Cádiz, Editorial R. Rodríguez, 1906.

Guía itinerario. Caravana automovilística: Excursión de gran turismo con la cooperación del "Automóvil Club de Barcelona" y con motivo de las bodas de S.M. el Rey (q.D.g) Barcelona-Madrid-Barcelona. 25 de Mayo a 3 de Junio de 1906, Barcelona, Editorial Tipolit Seix, 1906.

"UVE: Guía del Turista en España y Portugal", en Anuario de la Unión Velocipédica Española, Madrid, 1907.

Ibiza. Guía del turista. Arte: Arqueología, Agricultura, Comercio, Costumbres, Historia, Industria. Topografia, Barcelona, Imprenta de Joaquín Horta, 1909. 
Guía central continental de ferrocarriles: única guía oficial del Touring club HispanoPortugués y de la Sociedad de Turismo de Cádiz, Editado por la Agencia Central Continental, Madrid, Hijos de R. Álvarez, 1911.

Guía Ilustrada del Viajero: Madrid en la mano, Castellón Codorniú, Federico. Madrid, Artes Gráficas Mateu, 1911.

Guía de Espagne et Portugal. Manuel du voyageur, Baedeker, Karl. $4^{a}$ edición. Vol. 1. Leipzig: Karl Baedeker, 1913.

Guía-anuario-turista. Gonzalvo Burgoa, Celestino E. Madrid, Tipografía de M. Dávila, 1915.

Guía del turista. Mondariz-Vigo-Santiago. Madrid, Sucesores de Rivadeneyra, (1912) Guía de Hoteles de España, Sevilla: Tipografía de Manuel Carmona, 1917.

Les guides bleus: Espagne, Monmarché, Marcel. París: Librairie Hachette y Londres: Macmillan \& Co. LTD., 1927.

Les guides bleus: Espagne et Portugal, Monmarché, Marcel. París, Librairie Hachette, 191.

Anuario guía de las playas y balnearios de España, Madrid, Ed. Ibero-africano-americanas, 1924.

Novísima Guía de España y Portugal: manual del viajero y del turista, Beltrán, Francisco y Domenech, A. Barcelona, Enrique López Editor, 1924.

Guia Atlantic: carreteras de España, Atlantic Refining Company of Spain. Madrid, Imp. de J. Pueyo, 1927.

Guía Oficial de establecimientos balnearios españoles y aguas medicinales españolas, Asociación Nacional de Propaganda Balnearia. Madrid-Barcelona, Ed. Rudolf Mosse, 1927.

Guía oficial de la Exposición Internacional de Barcelona, 1929, Barcelona, Rudolf Mosse Ibérica editor, 1929.

España, paraíso del turista: guía descriptiva, Fernández Acevedo M. $2^{\mathrm{a}}$ edición. Madrid, (s/n), 1929.

Guía Oficial de Hoteles, Pensiones, Casa de viajeros, Restaurantes, Bares y Garajes, Patronato Nacional del Turismo. Madrid, Talleres Voluntad, 1929.

Guía general de líneas exclusivas de transporte en automóviles para viajeros, equipajes y mercancías de toda España. Patronato Nacional de Turismo, Madrid, Imprenta del P. de H. de Intendencia e intervención militares, 1930.

Los Hoteles de España: Guía oficial. 1931-1932, Patronato Nacional del Turismo. Dirección General de Turismo. Santander, Aldus S.A., 1932.

\subsection{Publicaciones periódicas y revistas}

Alrededor del mundo, Barcelona, Henrich y Cía., 1899-1930.

Aragón. Sindicato de Iniciativa y Propaganda de Aragón. Año I, núm. 1. De (octubre-1925) hasta año 43, núm. 286 (marzo 1968) Zaragoza: S.I.P.A, 1925-1968.

Boletín de la Sociedad Castellana de Excursiones, Sociedad Castellana de Excursiones. Valladolid: enero, febrero y marzo. 1903, año I, núms. 1, 2 y 3.

Boletín de la Sociedad Española de Excursiones, Sociedad Española de Excursiones. Madrid, Editores Hauser y Menet, 1892 - 1931. 
Canarias turista: Semanario ilustrado, Año I. Las Palmas: Tipografía del "Diario", septiembre 1910.

La Correspondencia de España: Diario, Año LVI, núm. 17.242, Edición de la noche. Madrid, 25 de abril 1905.

Estudios Turísticos, Madrid, Instituto Español de Turismo y Secretaria General de Turismo, 1976, 1980 y 1984.

Cultura Hispano-Americana, Pro-Patria. Madrid, Est. Tip de "El Liberal", 1913, Número extraordinario de la revista dedicado al turismo.

La Época: Diario, Núm. de 18.839 a 18.879. Madrid, Servicios de imprenta del diario "La época", 1905.

La Ilustración Española y Americana, Núm. de 14 a 65. Madrid, Abelardo de Carlos, 1869-1921.

Mediterráneo. Revista Ilustrada de Turismo, Año I, núm. 11. Barcelona, (s/n), 1926.

Mundo Español, Núm. 87. Dedicado a la exposición Internacional de Barcelona. Santiago de Chile: $(\mathrm{s} / \mathrm{n})$, diciembre 1928.

El Museo Universal, Madrid, Imprenta de Gaspar y Roig, 1857 - 1869.

Nuevo Mundo, Madrid, Nuevo Mundo, 1903 - 1931.

Patria, Comisaría Regia de turismo de España. Nottingham: Needham and Lugsdin, ltp, 1914, núm. 1, edición bilingüe (español / inglés).

Peñalara: Revista ilustrada de alpinismo, Año VI, núm. 68. Madrid, Sociedad Española de Alpinismo "Peñalara", 1919.

Pro-Turismo: Revista Mensual Ilustrada, Año I, núm. 1, 2 y 3. Madrid, (s/n), 1917-

1918. La revista de viajes: periódico ilustrado consagrado al turismo. Año VI, núm. 23. Madrid, Thos. Cook \& Son en colaboración con la CIA. Wagons-Lits, julio septiembre1929.

Stadium: Revista ilustrada, Motor-Turismo-Deportes. Año XI, núm. 334. Barcelona, (s/n), 1921.

Touring Club: revista mensual, Órgano oficial del Touring Club Español. Núm. 1, año 1. Madrid, Octubre, 1930.

Le Touriste. Espagne-Portugal, Revista mensual Ilustrada dedicada al fomento de los viajes por España y Portugal. Ferrant Janer, F. y Morales, Gonzalo. Núm. 1, año 1.

Madrid, Diciembre, 1905.

Turismo, Sociedad de Atracción de Forasteros. Núm. 4, año I. Madrid, Diciembre 1926.

El turista, periódico quincenal: Órgano de los Fondistas y Similares: cafés y restaurantes, Año 1, núm. 1. Madrid, Viernes, 9 de mayo de 1913.

El viajero, Año 1, núm. 4. Madrid, (s/n), 14 de julio de 1904.

Valencia Atracción: Portavoz de la Sociedad Valenciana Fomento del Turismo, Año I, núm. 4. Valencia: Semana Gráfica, diciembre 1926.

Viajes Marsans: revista de turismo, Viajes Marsans. Enero/marzo, núm. 1. Barcelona, Imprenta P.C.B.E Vidal Ribas, 1931.

Viajes por España, Madrid, Imprenta Prensa Nueva, 1928 -1930.

Los Viajes Prácticos: viajes-turismo-transportes. Revista mensual, Madrid, Exprinter, 1925-1929. 